Original Research Article

\title{
Comparison of the efficacy of budesonide by nebulizer, metered dose inhaler and dry powder inhaler in chronic stable bronchial asthma
}

\author{
Dilshad Ali Rizvi $^{1 *}$, Afroz Abidi ${ }^{1}$, Abhishek Agarwal' ${ }^{2}$, Ali Ahmad ${ }^{1}$
}

\begin{abstract}
${ }^{1}$ Department of Pharmacology, ${ }^{2}$ Department of Tuberculosis and Chest Diseases, Era's Lucknow Medical College \& Hospital, Sarfarazganj, Hardoi Road, Lucknow 226003, Uttar Pradesh, India
\end{abstract}

Received: 18 April 2018

Accepted: 22 May 2018

*Correspondence to: Dr. Dilshad Ali Rizvi, Email: dr.dilshadrizvi@ gmail.com

Copyright: (C) the author(s), publisher and licensee Medip Academy. This is an openaccess article distributed under the terms of the Creative Commons Attribution NonCommercial License, which permits unrestricted noncommercial use, distribution, and reproduction in any medium, provided the original work is properly cited.

\begin{abstract}
Background: The study has been performed to evaluate the efficacy of budesonide delivery by different form of devices like nebulizer, metered dose inhaler and dry powder inhaler to adult patients of chronic stable bronchial asthma. The changes in pulmonary function test parameters have been consider for evaluation.

Methods: This prospective study was undertaken to assess the relative efficiency of budesonide administered from devices like nebulizer, metered dose inhaler and dry powder inhaler in adult patients of chronic stable bronchial asthma. Fifty subjects where administered budesonide $(1 \mathrm{mg}$ ) via nebulizer, budesonide (400 microgram) by metered dose inhaler and dry powder inhaler consecutively each week for four weeks under direct supervision. To analyze the effect of budesonide delivered through different devices pulmonary function test was carried out on the subject before and one hour after administration of the drug on each visit.

Results: No significant difference in Peak expiratory flow rate $(\mathrm{P}=0.77)$, forced expiratory volume in one second $(\mathrm{P}=0.851)$, forced vital capacity $(\mathrm{P}=0.178)$ and forced expiratory volume in one second and forced vital capacity ratio $(\mathrm{P}=0.298)$ was seen after giving budesonide by different devices.

Conclusions: Budesonide delivered by different devices (nebulizer, metered dose inhaler, and dry powder inhaler) have similar effect on lung function in patients of chronic stable bronchial asthma. In the daily clinical practice, the correct choice of an inhaler device should be related with the patient's characteristics. They may be used interchangeably depending on availability, cost and compliance of the patients.
\end{abstract}

Keywords: Asthma, Budesonide, Comparative study, Inhaled corticosteroid

\section{INTRODUCTION}

Bronchial asthma is a serious global health problem. People of all ages in countries throughout the world are affected by this chronic airway disorder that, when uncontrolled, can place severe limits on daily life and sometimes fatal. Asthma is a significant burden not only in terms of health care costs but also of lost productivity and reduced participation in family life.

The major clinical features of asthma are wheezing, shortness of breath, and cough. ${ }^{1}$
Pharmacologic management includes the use of control agents such as inhaled corticosteroids, long-acting bronchodilators (beta-agonists and anticholinergics), theophylline, leukotriene modifiers, and more recent strategies such as the use of anti-immunoglobulin E ( $\mathrm{IgE}$ ) antibodies (omalizumab) and anti-IL-5 antibodies in selected patients. ${ }^{1}$

Inhaled corticosteroids are the most effective antiinflammatory medications available for the treatment of asthma and represent the mainstay of therapy for most patients with the disease. Low-dose inhaled corticosteroid monotherapy is recommended as first-line maintenance 
therapy for most children and adults with asthma. Regular use of inhaled corticosteroid has been shown to reduce symptoms and exacerbations and improves lung function and quality of life. ${ }^{2}$

Inhaled medications for asthma are available as pressurized metered dose inhaler, metered dose inhaler with spacer, breath-actuated metered dose inhaler, dry powder inhalers, soft mist inhalers and nebulized or wet aerosols. Inhaler devices differ in their efficacy of drug delivery to the lower respiratory tract, depending on the form of the devices, formulation of medication, particle size, velocity of the aerosol cloud or plume and ease with which device can be used by the majority of patients

The study has been performed to evaluate the efficacy of budesonide delivery by different form of devices like nebulizer, metered dose inhaler and dry powder inhaler to adult patients of chronic stable bronchial asthma. The changes in pulmonary function test parameters have been consider for evaluation.

\section{METHODS}

This prospective eighteen months study was conducted among clinically diagnosed patients of chronic stable bronchial asthma from out -patient department of Tuberculosis and Chest Diseases, Era's Lucknow Medical College and Hospital, Lucknow. Individuals of either sex aged 18 years and above, who were residents of the local area and had a history of bronchial asthma for at least 6 months comprised the study unit. Approval for the study from the Institutional ethical committee was obtained and written and informed consent from all patients was taken.

Sample size was calculated to be 36 on the basis of prior observations reported in a previous study using the formula: $\mathrm{n}-\left(\sigma_{1}{ }^{2}+\sigma_{2}{ }^{2}\right)(\mathrm{Z} 1-\alpha / 2+\mathrm{Z} 1-\beta)^{2} / \mathrm{d}^{2}$ where $\sigma 1=3.4$, $\sigma 2=4.7, d=3.4, Z 1-\alpha / 2=1.96, Z 1-\beta=1.28, \alpha=.05$ and $\beta=0.1$ (power $90 \%) .{ }^{3}$ But assuming loss to follow up cases to be $30 \%$ (10\% for each step), the initial recruitment was calculated to be 46 which was further rounded off to 50 cases.

The subjects fulfilling the following criteria were considered to be suffering from chronic stable bronchial asthma as stated by American Thoracic society $1987 .{ }^{4}$

- History suggestive of bronchial asthma.

- No acute exacerbation within the past one month. (Exacerbations: - are episodes of progressive increase in shortness of breath, cough, wheezing, or chest tightness, or some combination of these symptoms

- No history of receiving any corticosteroid therapy for past one month.

- Baseline forced expiratory volume in one second $\left(\mathrm{FEV}_{1}\right)$ less than $80 \%$ of predicted value.

- Increase in $\mathrm{FEV}_{1}$ equal or more than to $12 \%$ and peak expiratory flow rate (PEFR) equal or more than $20 \%$ of baseline value 15 minutes after bronchodilator therapy.

Patients with past history of hypersensitivity to budesonide, history of treatment of asthma within four weeks prior to study were excluded. Pregnant and lactating females, subjects with hepatic, cardiac, renal and respiratory disorders and those with an upper respiratory tract or acute sinus infection within four weeks prior to enrollment were also excluded. Individuals with a smoking history of >10 pack-years and those on immunotherapy who required a change in dosage regimen within 12 weeks prior to enrollment were also excluded.

\section{Study design}

All study subjects underwent pulmonary function tests before and after drug administration and received the following drugs.

- $\quad$ First Visit (day-1): Inhaled salbutomol 200mcg was administered to assess bronchodilator reversibility and to fulfil criteria of bronchial asthma.

- $\quad$ Second visit (day-8): Budesonide (Budecort) $1 \mathrm{mg}$ by nebulizer single (After one week) dose.

- $\quad$ Third visit (day 15): Budesonide (Budecort) 400mcg by metered dose (After another one week) inhaler single dose.

- $\quad$ Fourth visit (day 22): Budesonide (Budecort) $400 \mathrm{mcg}$ by dry powder (After another one week) inhaler single dose.

After a standardized initial evaluation, which include complete history, clinical examination, investigations, asthma symptom score and spirometry, patients were requested to follow up every week for 3 weeks. Each patient was given a card in which as needed salbutamol inhalation was mentioned by patients himself and patients were requested to bring the card along with them when they came after one week. Each patient was given a diary card to encircle asthma symptoms.

The severity of Asthma was assessed by symptom score as mentioned by P. Calverley et al, and included major complains of asthma i.e.

1. Shortness of breath,

2. Cough

3. Chest tightness

4. Night time awakening.

The individual score of above four parameters were added up to get the cumulative asthma score. ${ }^{5}$

Spirometric measurements were performed in department of Tuberculosis and Chest Diseases in Era's Lucknow Medical College and Hospital Lucknow. Spirometry was performed with standard techniques and evaluated for validity according to American Thoracic Society criteria. ${ }^{6}$ The equipment used for spirometry was Medspiror by Medsystems Private Limited, Chandigargh. 
At least three spirometry maneuvers were done and highest $\mathrm{FEV}_{1}$ value was noted. Patients who had $\mathrm{FEV}_{1}$, less than $80 \%$ of predicted value were administered inhaled salbutamol $200 \mathrm{mcg}$ by nebulizer. 15 minutes after salbutomol administration spirometry was repeated and patient who had an increase of at least $12 \%$ absolute $\mathrm{FEV}_{1}$ and at least $20 \%$ PEFR were labelled as suffering from bronchial asthma and enrolled in the study. Investigation reports including pre and post medication pulmonary function test (PFT) were collected. Patients fulfilling inclusion/exclusion criteria were enrolled in to the study. Pre and post medication pulmonary function test (PFT) reports were collected. Thus, in all, patients had to visit the department for 4 times including nomination, registration and 3 follow up visits.

Data entry and statistical analysis was done using statistically package of social science (SPSS) software (version 20.0). Paired " $\mathrm{t}$ " test, ANOVA and post hoc turkey's test were used. $\mathrm{P}$ values less than 0.05 were considered significant.

\section{RESULTS}

Initially 50 Patients were enrolled in the study out of which, 3 did not turn up after second visit and 2 did not turn up after third visit. None of the Patients experienced an acute exacerbation of asthma during the study period thus finally 5 patents were excluded due to loss to follow up and the data of the remaining 45 subject ( 27 males and 18 females) were analysed $24(53.3 \%)$ individuals were aged between $18-40$ years $17(37.7 \%)$ individuals were aged between 41-61 years and $4(8.9 \%)$ individuals were agreed between 61-70 years. The mean age of the patients was found to be 42 years.

Mean asthma scores calculated from diary card entries varied between 1.97 to 2.09 on days of visits (Table 1). There was no significant difference in patient's asthma symptom score per week at day of 1, 8, 15 and 22 ( $\mathrm{P}>0.05)$. Since there was no significant change in pulmonary function test parameters (before the giving budesonide) at week-2, week-3, week-4, which shows that the patients were suffering from chronic stable bronchial asthma and there was no significant modification in the disease process during the course of the study. No significant change in the asthma symptom scores and use of rescue medication during the study periods also shows that there was no acute exacerbation and the patients were stable (Table 1).

Table 1: Asthma symptom score.

\begin{tabular}{|c|c|c|c|c|c|c|}
\hline & & Shortness of breath & cough & Chest tightness & Night time awakening & Total \\
\hline Day-1 & & $0.78 \pm 0.73$ & $0.68 \pm 0.63$ & $0.36 \pm 0.48$ & $0.26 \pm 0.44$ & $2.09 \pm 0.79$ \\
\hline Day-8 & & $0.73 \pm 0.62$ & $0.71 \pm 0.59$ & $0.40 \pm 0.49$ & $0.24 \pm 0.43$ & $2.08 \pm 0.70$ \\
\hline Day-15 & & $0.76 \pm 0.61$ & $0.64 \pm 0.57$ & $0.33 \pm 0.47$ & $0.24 \pm 0.43$ & $1.98 \pm 0.75$ \\
\hline Day-22 & & $0.73 \pm 0.57$ & $0.68 \pm 0.63$ & $0.33 \pm 0.47$ & $0.22 \pm 0.42$ & $1.97 \pm 0.72$ \\
\hline \multirow{2}{*}{ ANOVA } & $\mathrm{F}=$ & 0.055 & 0.161 & 0.179 & 0.027 & 0.289 \\
\hline & $\mathrm{P}=$ & 0.983 & 0.932 & 0.911 & 0.994 & 0.833 \\
\hline
\end{tabular}

Table 2: Effect on peak expiratory flow rate (PEFR) (Predicted \%) after giving Budesonide by different devices.

\begin{tabular}{|c|c|c|c|}
\hline & $\begin{array}{l}\text { Pre- } \\
\text { treatment } \\
(\text { Mean } \pm \text { SD) }\end{array}$ & $\begin{array}{l}\text { Post } \\
\text { treatment } \\
(\text { Mean } \pm \text { SD })\end{array}$ & $\begin{array}{l}\% \\
\text { Changes }\end{array}$ \\
\hline Nebulizer & $39.71 \pm 4.03$ & $43.49 \pm 3.76$ & $9.72 \pm 3.39$ \\
\hline $\begin{array}{l}\text { Metered Dose } \\
\text { Inhaler (MDI) }\end{array}$ & $40.33 \pm 4.11$ & $43.04 \pm 4.18$ & $6.79 \pm 2.01$ \\
\hline $\begin{array}{l}\text { Dry powder } \\
\text { Inhaler (DPI) }\end{array}$ & $40.18 \pm 3.59$ & $43.01 \pm 3.13$ & $9.11 \pm 3.28$ \\
\hline \multirow{2}{*}{ ANOVA } & 0.341 & 0.262 & \\
\hline & 0.712 & 0.77 & \\
\hline
\end{tabular}

Pre-treatment values of peak expiratory flow rate varied between $32-48 \%, 33-51 \%, 35-50 \%$ before giving budesonide by nebulizer (week-2), metered dose inhaler (week-3) and dry powder inhaler (week-4) respectively. There was no significant difference in PEFR values at week 2, 3, and 4, before giving the drug by different devices $(\mathrm{P}>0.05)$ (Table 2$)$.

Table 3: Effect on forced expiratory volume in 1 second (FEV1) (predicted \%) after giving Budesonide by different devices.

\begin{tabular}{|c|c|c|c|}
\hline & $\begin{array}{l}\text { Pre- } \\
\text { treatment } \\
(\text { Mean } \pm \text { SD })\end{array}$ & $\begin{array}{l}\text { Post } \\
\text { treatment } \\
(\text { Mean } \pm \text { SD) }\end{array}$ & $\begin{array}{l}\% \\
\text { changes }\end{array}$ \\
\hline Nebulizer & $67.36 \pm 2.97$ & $72.58 \pm 3.37$ & $7.78 \pm 3.39$ \\
\hline $\begin{array}{l}\text { Metered Dose } \\
\text { Inhaler (MDI) }\end{array}$ & $67.42 \pm 4.81$ & $72.13 \pm 4.79$ & $7.02 \pm 2.21$ \\
\hline $\begin{array}{l}\text { Dry powder } \\
\text { Inhaler (DPI) }\end{array}$ & $68.18 \pm 4.78$ & $72.16 \pm 4.96$ & $5.85 \pm 1.70$ \\
\hline \multirow{2}{*}{ ANOVA } & 0.572 & 0.161 & \\
\hline & 0.566 & 0.851 & \\
\hline
\end{tabular}

Pre-treatment values of forced expiratory volume in 1 second varied between $61-74 \%, 60-77 \%, 62-75 \%$ and 58 $77 \%$ before giving budesonide by nebulizer (week-2), metered dose inhaler (week-3), and dry powder inhaler (week-4) respectively. There was no significant difference 
in FEV1 values at week 2, 3 and4 before giving the drug by different devices $(\mathrm{P}>0.05)$ (Table 3$)$.

Pre-treatment values of forced vital capacity varied between $81-97 \%, 82-101 \%$ and $84-102 \%$ before giving budesonide by nebulizer (week-2), metered dose inhaler (week-3), and dry powder inhaler (week-4) respectively. There was no significant difference in FVC values at week 2,3 , and 4 before giving the drug by different devices (P>0.05) (Table 4).

Table 4: Effect on forced vital capacity (FVC) (predicted \%) after giving Budesonide by different devices.

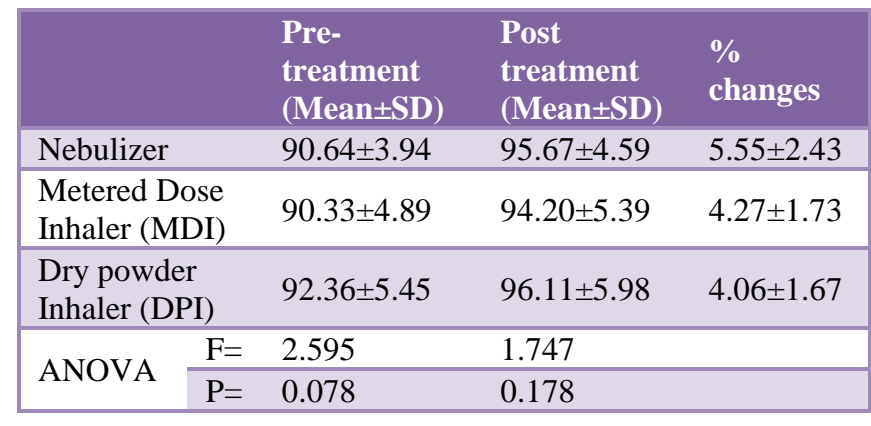

Pre-treatment values of FEV1/FVC varied between 0.67 $0.83 \%, 0.72-0.84 \%$ and $0.65-0.83 \%$ before giving budesonide by nebulizer (week-2), metered dose inhaler (week-3), and dry powder inhaler (week-4) respectively. There was no significant difference in FEV1/FVC values at week 2,3 , and 4 , before giving the drug by different devices $(\mathrm{P}>0.05)$ (Table 5).

Table 5: Effect on FEV1/FVC (predicted \%) after giving Budesonide by different devices.

\begin{tabular}{|c|c|c|c|c|}
\hline & & $\begin{array}{l}\text { Pre- } \\
\text { treatment } \\
(\text { Mean } \pm \text { SD })\end{array}$ & $\begin{array}{l}\text { Post } \\
\text { treatment } \\
(\text { Mean } \pm \text { SD) }\end{array}$ & $\begin{array}{l}\% \\
\text { changes }\end{array}$ \\
\hline Nebulizer & & $0.74 \pm 0.03$ & $0.76 \pm 0.04$ & $2.11 \pm 1.14$ \\
\hline $\begin{array}{l}\text { Metered D } \\
\text { Inhaler (M }\end{array}$ & & $0.75 \pm 0.03$ & $0.76 \pm 0.03$ & $2.63 \pm 1.61$ \\
\hline $\begin{array}{l}\text { Dry powd } \\
\text { Inhaler (D }\end{array}$ & & $0.73 \pm 0.04$ & $0.75 \pm 0.04$ & $1.73 \pm 1.03$ \\
\hline \multirow{2}{*}{ ANOVA } & $\mathrm{F}=$ & 4.412 & 1.22 & \\
\hline & $\mathrm{P}=$ & 0.014 & 0.298 & \\
\hline
\end{tabular}

One hour after giving budesonide by nebulizer (week-2), metered dose inhaler (week-3),) and dry powder inhaler (week-4) there was highly significant increase in PEFR $(\mathrm{P}<0.001), \quad$ FEV1 $\quad(\mathrm{P}<0.001), \quad$ FVC $\quad(\mathrm{P}<0.001)$ and FEV1/FVC $(\mathrm{P}<0.001)$,

The percentage change in PEFR was highest after giving budesonide by nebulizer (38-50\%) by dry powder inhaler $(34-50 \%)$, and metered dose inhaler (36-50\%). However, there was no significant difference in the PEFR after giving budesonide by any of the devices $(\mathrm{P}>0.05)$.
The post treatment values of FEV1 ranged between 67 $82 \%, 64-83 \%$ and $65-79 \%$ for nebulizer metered dose inhaler, and dry powder inhaler respectively, the difference being statistically insignificant $(\mathrm{P}>0.05)$.

The percentage change in FVC ranged between $88-104 \%$, $87-105 \%$ and $86-106 \%$ by nebulizer, metered dose inhaler, and dry powder inhaler respectively, the difference being statistically insignificant $(\mathrm{P}>0.05)$.

The percentage change in FEV1/FVC ranged between $0.69-0.84 \%, 0.71-0.85$ and $0.67-0.84 \%$ by nebulizer, metered dose inhaler and dry powder inhaler respectively, the difference being statistically insignificant $(\mathrm{P}>0.05)$.

The pulmonary function parameters showed a highly significant increase one hour after giving budesonide by any of the devices evaluated. There was no significant difference in post treatment values of peak expiratory flow rate $(\mathrm{P}=0.77)$, forced expiratory volume in one second $(\mathrm{P}=0.95)$, forced vital capacity $(\mathrm{P}=0.24)$ and forced expiratory volume in one second and forced vital capacity ratio $(\mathrm{P}=0.22)$ after giving budesonide by nebulizer, metered dose inhaler and dry powder inhaler respectively at day 8, 15 and 22. This shows a similar efficacy of budesonide delivered via the different devices studied.

\section{DISCUSSION}

As per the literature review we have not come across any Indian study comparing clinical efficacy of budesonide delivered via nebulizer, meter dose inhaler and dry powder inhaler in patients of chronic stable bronchial asthma. In this study we have tried to compare the effect of budesonide delivered via nebulizer, metered dose inhaler, and by dry powder inhaler on lung functions and proclaim that these devices have a similar effect on the lung function in patients of chronic stable bronchial asthma. Higher incidence of chronic stable bronchial asthma was found among those aged between 18 to 40 years in this study. ${ }^{7}$ These finding corroborates with the results of previous surveys which show that bronchial asthma occurs in all ages with one half cases occurring before age of 10 years and another third before age 40 years. Out of 45 patients enrolled the majority $(60 \%)$ were males in the current study. Previous studies however have shown that in adulthood prevalence of asthma is greater in women than men, reason for which is not clear. ${ }^{8}$ The reason for higher enrollment of males in this study is partly due to exclusion of pregnant and lactating women and partly due to the larger male and female sex ratio as per Census. ${ }^{9}$ One hour after giving budesonide by nebulizer (week-2), metered dose inhaler (week-3), and dry powder inhaler (week-4) there was highly significant increase in PEFR in this study. The percentage change in peak expiratory flow rate was $9.27 \pm 3.39$ with nebulizer, $6.79 \pm 2.01$ with metered dose inhaler, and $9.11 \pm 3.28$ with dry powder inhaler. Edinger et al, demonstrated that the PEFR predicted percentage increased from 42 to $56 \%$ after a single dose of budesonide given by nebulizer although the change was 
insignificant. ${ }^{10}$ This can be attributed to the smaller sample size (16 patients) and higher proportion of females (Female: male ratio=13:3) in their study. The effect of gender on response to inhaled corticosteroid in patients of asthma needs to be explored. Donald in his study shown the use of dry powder inhaler where it was found that peak inspiratory flow rate was sub optimal (less than 60 liters/minute). It was concluded that if the peak inspiratory flow rate is less than 60 liters/minute, the patient may not achieve optimal clinical benefit and a different delivery system, such as a metered-dose or soft-mist inhaler or nebulized therapy, should be considered. ${ }^{11}$

Several studies have demonstrated an increase in peak expiratory flow rate after giving budesonide by nebulizer, metered dose inhaler, metered dose inhaler with spacer and dry powder inhaler over a period of 1 to 12 weeks. ${ }^{12-16}$ No significant difference in the PEFR was found after giving budesonide by any of the different devices used in this study which is in agreement with the study of Bisgaard et al, that compared the effect of budesonide given as nebulized suspension verses metered dose inhaler in adult asthmatics. ${ }^{12}$ Spirometry at their clinic revealed no statistically significant difference between the treatments. Effect of $1 \mathrm{mg}$ budesonide by nebulizer was significantly more than that of budesonide by metered dose inhaler plus spacer only in evening peak expiratory flow rate. Engel et al, also demonstrated that there was no significant difference in peak expiratory flow rate at clinic and evening peak exploratory flow rate after giving budesonide by metered dose inhaler or dry powder inhaler, however morning peak expiratory flow rate found from patient's diaries showed significantly higher values in the group receiving budesonide through dry powder inhaler. ${ }^{13}$ Reason of different effects of delivery devices on morning evening peak expiratory flow rate needs to be further investigated. One hour after giving budesonide by nebulizer (week-2), metered dose inhaler (week-3), and dry powder inhaler (week-4) there was a highly significant increase in FEV1 in this study. Kerwin et al, observed a significant increase in FEV1 when budesonide was given by dry powder inhaler as compared to placebo. ${ }^{13}$ There was no significant difference found in the FEV1 after giving budesonide by any of the devices used in this study. Engel et al, compared inhaled budesonide delivered either via pressurized metered dose inhaler or turbuhaler and found that there was no significant difference in FEV1 between the two treatments. Bisgaard et al, compared the efficacy of budesonide as a nebulized suspension versus pressurized metered dose inhaler in adult asthmatics and revealed no statistically significant difference between the treatments. ${ }^{12.13}$ One hour after giving budesonide by nebulizer (week-2), metered dose inhaler (week-3), dry powder inhaler (week-4) forced vital capacity also increased significantly. Although the percentage change in forced vital capacity was highest with nebulizer, followed by metered dose inhaler, and dry powder inhaler but there was no significant difference in the FVC after giving budesonide by any of the devices. Engel et al, compared inhaled budesonide delivered via pressurized metered dose inhaler and turbuhaler and found no statistically significant differences in FVC. Mario Cazzola et al, studied Onset of action of budesonide/formoterol (BF) Spiromax DPI compared with budesonide/formoterol Turbuhaler DPI in patients with COPD and found that there was rapid onset of action of formoterol when combined with budesonide in patients with COPD and indicates that the onset of bronchodilation induced by BF Spiromax is faster than that elicited by BF Turbuhaler. Intriguingly, BF Spiromax elicited also a greater increase in FEV1 when compared with BF Turbuhaler. ${ }^{13,17}$ One hour after giving budesonide by nebulizer (week-2), metered dose inhaler (week-3), and dry powder inhaler (week-4) there was highly significant increase in forced expiratory volume in one second and forced vital capacity ratio (FEV1/FVC). There was no significant difference found in the FEV1/FVC after giving budesonide by any of the devices. Previous studies on inhaled budesonide by different devices in patients of chronic stable bronchial asthma have not reported the effect on FEV1/FVC. The present study found no significant differences on spirometric variables after giving budesonide via nebulizer, metered dose inhaler, and dry powder inhaler.

In the daily clinical practice, the correct choice of an inhaler device should be related with the patient's characteristics. ${ }^{18,19}$ The patient's age, cognitive status, visual acuity, manual dexterity and strength, and ability to coordinate actuation of the inhaler with inhalation may be as important as disease severity in determining the appropriate approach to delivery of medication. For several patients, using a nebulizer alone or in addition to a pMDI or a DPI provides an easy-to-use and cost-effective therapy. ${ }^{17,18}$

\section{ACKNOWLEDGEMENTS}

The authors are thankful to Prof. Dr. Ali Ahmad, (HOD, Department of Pharmacology, Era's Lucknow Medical College Lucknow) for his utmost help and guidance and Dr. Zeeshan Haider Zaidi Lecturer/statistician, Department of Community Medicine, Era's Lucknow Medical College Lucknow for his expert help in statistical analysis.

\section{Funding: No funding sources Conflict of interest: None declared \\ Ethical approval: The study was approved by the Institutional Ethics Committee}

\section{REFERENCES}

1. Morris MJ. Asthma Treatment and Management. Available http://emedicine.medscape.com/article/296301treatment Updated: Jun 16, 2016

2. Harold K, Mazza J. Practical guide for allergy and immunology in Canada. Allergy, Asthma and clinical Immunology. 2011;7(1): S2(suppl-II). 
3. Dane E, Funda C, Esra KU, Eser GY, Mehmet K, Ercument E, et al. Clinical effectiveness of nebulised budesonide in the treatment of acute asthma attacks. Tuberkuloz ve Torak Dergisti. 2006;54(2):128-36.

4. American Thoracic Society: Standards for the diagnosis and care of patients with chronic obstructive pulmonary disease and asthma. Am Rev Respir Dis. 1987;136:225-43.

5. Calverley P, Pauwels R, Lofdahl CG, Svensson K, Higenbottam T, Carlsson IG, et al. Relationship between respiratory symptoms and medical treatment in exacerbations of COPD. Eur Respir J. 2005;26:40613.

6. Standardization of spirometry, 1994 update. American Thoracic Society. Am J Resspir Crit Care Med. 1995;152(3):1107-36.

7. Barnes PJ. Asthma, In, Harrison's principle of Internal Medicine (Fauci, Braunwald, Kasper, Hauser, Longo, Jameson, Loscalzo) Diseases of Respiratory System Asthma $17^{\text {th }}$ Edition, McGraw Hill, New Delhi, 2008;1596.

8. GINA Asthma Management and Prevention, Globalinitiative for Asthma, Global strategy for asthma management and prevention; 2008:64.

9. Census of India: Provisional Population Total. Registrar and Census Commissioner for India, New Delhi; 2001.

10. Edinger D, Coskun F, Kunt UE, Giirdal YE, Karadag $\mathrm{M}$, Ege E, et al. Clinical effectiveness of nebulized budesonide in the treatment of acute asthma attacks. Turberk Toraks. 2006;54(2):128-36.

11. Mahler DA. Peak Inspiratory Flow rate as a criterion for dry powder inhaler use in chronic obstructive pulmonary disease. Ann Am Thorac Soc. 2017 July;14(7):1103-7.

12. Bisgaard H, Nikander K, Munch E. Comparative study of budesonide as a nebulized suspension vs pressurized metered dose inhaler in adult asthamatics. Respiratory Medicine. 1998;92:44-9.
13. Engel T, Heinig JH, Malling HJ, Scharling B, Nikander K, Madsen F. Clinical comparison of inhaled budesonide delivered either via pressurized metered dose inhaler or Turbuhaler. Allergy. 1989;44:220-5.

14. Kerwin EM, Pearlman DS, De Guia T, Carlsson LG, Gillen M, Uryniak T, et al. Evaluation of efficacy and safety of budesonide delivered via two dry powder inhalers. Curr Med Res Opin. 2008;24(5):1497-510.

15. Morice AH, Hochmuth L, Ekelund J, Thoren A, Puterman AS. Comparable long term safety and efficacy of a novel budesonide/formoterol pressurized metered dose inhaler versusbudesonide/formoterol Turbuhaler in adolescents and adults with asthma. Pulm Pharmacol Ther. 2008;21(1):32-9.

16. Volovitz B. inhaled budesonide in the management of acute worsening and exacerbations of asthma: a review of the evidence. Respir Med. 2007 Apr;101(4):685-95.

17. Cazzola M, Ora J, Di Paolo A, Puxeddu E, Calzetta L, Rogliani P. Onset of action of budesonide/formoterol Spiromax ${ }^{\circledR}$ compared with budesonide/formoterol Turbuhaler® in patients with COPD. Pulmonary pharmacology \& therapeutics. 2016 Aug 1;39:48-53.

18. Cazzola M, Rogliani P. Controversies in COPD. Chapter 15-Inhaled medication: which device for which patient? ERS Monogr. 2015;69:213-23.

19. Fromer L, Goodwin E, Walsh J. Customizing inhaled therapy to meet the needs of COPD patients, Postgrad. Med. 2010;122:83-93.

Cite this article as: Rizvi DA, Abidi A, Agarwal A, Ahmad A. Comparison of the efficacy of budesonide by nebulizer, metered dose inhaler and dry powder inhaler in chronic stable bronchial asthma. Int J Basic Clin Pharmacol 2018;7:1333-8. 